\title{
Políticas Públicas de Esporte e Lazer no Brasil: Uma Proposta Teórico-Metodológica de Análise
}

\author{
Fernando Augusto Starepravo* \\ Juliano de Souza** \\ Wanderley Marchi Junior ${ }^{* * *}$
}

\begin{abstract}
Resumo: O presente ensaio pretende contribuir com uma leitura mais refinada das políticas públicas de esporte e lazer por parte dos especialistas, através de algumas reflexões, conceitos e procedimentos metodológicos, que constituem parte fundamental das ferramentas de pesquisa do pesquisador social, particularmente aqueles que buscam uma leitura sociocultural do esporte, do lazer e das temáticas correlatas. Para tanto revisitamos alguns autores do campo científico/acadêmico da Educação Física, bem como recorremos a alguns agentes de outras áreas do conhecimento, que com suas contribuições podem auxiliar na superação da proliferação horizontal da produção científica da área, promovendo seu crescimento vertical em qualidade.
\end{abstract}

Palavras-chave: Políticas públicas. Esportes. Atividades de Lazer. Métodos.

\section{INTRODUÇÃo}

Políticas públicas de esporte e lazer no Brasil. Talvez não haja hoje um tema, dentro do campo científico/acadêmico da Educação Física, tão em voga quanto esse. Isso porque completou-se um ciclo político de oito anos de existência do Ministério do Esporte, e nesse período foram várias as ações desse órgão que motivaram o olhar dos pesquisadores, seja através da criação de uma Rede que apóia diretamente esse lócus de pesquisa, pela implementação de políticas públicas ditas inovadoras, pela possibilidade dada de participação

\footnotetext{
'Universidade Estadual de Maringá (UEM) / Universidade Federal do Paraná (UFPR). Maringá, PR, Brasil. E-mail: fernando.starepravo@hotmail.com

"Universidade Federal do Paraná (UFPR). Curitiba, PR, Brasil. E-mail: julianoedf@yahoo.com.br "'Universidade Federal do Paraná (UFPR). Curitiba, PR, Brasil. E-mail: marchijr@ufpr.br
} 
dos diferentes grupos sociais na formulação dessas políticas, ou ainda por ter "abraçado a causa" da realização de megaeventos esportivos no país.

Especialmente o último ponto, dos megaeventos esportivos, tem feito com que outras pessoas, grupos e instituições passem a se atentar com as políticas públicas de esporte e lazer no Brasil. Afinal, esse tipo de ação acaba tendo grande repercussão midiática e simbólica. Isso por sua vez, acaba repercutindo dentro e fora do país, e é tomado como assunto a ser discutido nos mais diferentes círculos sociais, desde a mídia, passando pelo âmbito científico/ acadêmico, até chegar aos círculos de amizade menos formais, como no bate-papo com o vizinho ou em "calorosas" discussões em uma mesa de bar.

Isso acaba revelando pontos positivos e negativos. Positivos no sentido de que a sociedade como um todo passa a discutir questões que até então estavam restritas a um conjunto de especialistas. Esses especialistas, por outro lado, devem se policiar de sua rigorosidade científica para não correr o risco de incorporar a discurso do senso comum e simplesmente ecoar discursos contra ou a favor de determinada causa política. Cabe e espera-se deles um olhar mais refinado, pautado na reflexão e no conhecimento já produzido ${ }^{1}$.

Nesse caso, e com base nos referenciais que serão desenvolvidos no texto, logo nos posicionamos no sentido de pensar as políticas públicas de esporte e lazer para além da política pública em si, o programa esportivo ou a iniciativa pública voltada a atender o cidadão no seu direito ao lazer como fenômenos estanques ou isolados de um contexto social. A política pública muitas vezes é apenas a parte mais visível de todo um processo desenvolvido num espaço social específico, que comporta disputas, relações, alianças, decisões estratégicas e também não planejadas. Em suma, escrever

\footnotetext{
${ }^{1}$ Marchi Jr. (2006) ao explicitar alguns procedimentos de pesquisa na sociologia do esporte faz uma analogia entre o objeto de pesquisa e uma pedra bruta. A partir da pesquisa sociológica espera-se que a pedra bruta seja transformada em algo belo, agradável, através do chamado "artesanato intelectual". Nesse sentido, quando falamos em olhar mais refinado no presente texto nos referimos ao produto final da pesquisa, que parte da pedra bruta apontada por Marchi Jr. (2006) e se transforma numa leitura mais refinada dos acontecimentos sociais.
} 
sobre políticas públicas de esporte e lazer requer mapear o espaço social onde esta é produzida, avançar no entendimento das relações entre os agentes, até finalmente compreender quais as políticas que foram efetivadas, aquelas que foram preteridas, as que obtiveram êxito e aquelas que não passaram de propostas.

Esse processo pode começar ancorado no conceito de campo político/burocrático, um espaço que supõe a dissociação da posição e de seu ocupante, da função e do funcionário, do interesse público e dos interesses privados, mas que paradoxalmente funciona como um metacampo do poder, até porque a gênese da ordem pública vem acompanhada da aparição e acumulação de um "capital público" (BOURDIEU, 2005, p. 68). Cada área no interior do campo político/ burocrático, por sua vez, pode ser entendida como um subcampo político/burocrático, onde as especificidades da área de atuação do Estado delimitam o espaço social de atuação dos agentes a ela vinculados.

Estamos falando, portanto, entre outros, de um subcampo político/burocrático do esporte e lazer, e não apenas das políticas públicas de esporte e lazer. Essas últimas seriam o produto do espaço social, que normalmente é consumido por agentes externos a ele: a população em geral. A produção, por outro lado, respeita lógicas e disputas internas ao subcampo. Aqui talvez exista uma (de) limitação do olhar, já que buscamos entender a lógica e o produto do subcampo, sem, porém, observar com mais afinco sua repercussão, que se dá para além do subcampo.

A tarefa de compreender o subcampo, entretanto, é complexa (até mesmo pela complexidade do Estado moderno) e por vezes limitada, dada a posição de quem está observando, ou o lugar de onde se está falando. Para minimizar as dificuldades, e tentar avançar nessa compreensão, fazem-se necessárias ferramentas complementares nessa empreitada. São questões e conceitos importantes à compreensão do Estado, uma instituição social moderna, com funções de manutenção e regulação social, dos seus respectivos 
aparatos de intervenção social - aqui especificamente as políticas sociais - e dos mecanismos constitucionais de proteção ao cidadão, legalmente inscritos como direitos sociais ${ }^{2}$.

É exatamente nesse sentido que propomos o presente ensaio, que visa contribuir com uma leitura mais refinada das políticas públicas de esporte e lazer por parte dos especialistas, através de algumas reflexões, conceitos e procedimentos metodológicos, que constituem parte das ferramentas de pesquisa do pesquisador social, particularmente aqueles que buscam uma leitura sociocultural do esporte, do lazer e das temáticas correlatas.

Para tanto revisitamos alguns autores do campo científico/ acadêmico da Educação Física, bem como recorremos a alguns agentes de outras áreas do conhecimento, que com suas contribuições podem auxiliar na superação da proliferação horizontal da produção científica da área, promovendo seu crescimento vertical, em qualidade (MELO, 1999).

\section{ESTADO E POLÍTICAS PÚBLICAS: UM OLHAR CONCEITUAL E METODOLÓGICO}

Voltando um pouco no tempo, temos que o desenvolvimento capitalista sempre esteve intimamente ligado ao Estado e na medida em que as economias se desenvolveram em todo o mundo, o setor público cresceu em importância em todas as sociedades (CARNOY, 1990). A própria formação do Estado e sua consolidação estiveram ligadas a questões econômicas, como o surgimento da moeda, a substituição da economia de troca e o monopólio econômico (ELIAS, 1993). Se no decorrer do surgimento e desenvolvimento do Estado

\footnotetext{
${ }^{2}$ Os direitos estão ligados à noção de cidadania. Segundo Menicucci (2006), costuma-se desdobrar a cidadania em três conjuntos de direitos: os direitos civis, relacionados à liberdade individual (ir e vir, liberdade de pensamento e fé, direito a propriedade, entre outros); os direitos políticos, relacionados ao direito de exercício do poder político (participação no governo, direito de votar e ser votado); e os direitos sociais, definidos por Marshall (1967), como o direito de participar por completo da herança social, levando a vida de um ser civilizado, de acordo com os padrões prevalecentes na sociedade.
} 
moderno, esse sempre teve um papel de destaque nas várias sociedades, hoje se pode dizer que ele é decisivo para os rumos da sociedade global ${ }^{3}$.

$\mathrm{Na}$ avançada economia globalizada em que vivemos, o Estado tem importância indiscutível em muitos aspectos da vida social, "não apenas político, como econômico (produção, finanças, distribuição), ideológico (educação escolar, os meios de comunicação) e quanto à força legal (polícia, forças armadas)" (CARNOY, 1990, p. 9).

Em períodos históricos anteriores, especialmente durante o século XIX, o Estado desempenhava um papel relevante, e mesmo sendo vital para o crescimento das sociedades, sua ação não era tão fortemente determinante para a sociedade quanto nas últimas décadas. Atualmente, "o Estado parece deter a chave para o desenvolvimento econômico, para a segurança social, para a liberdade individual e, através da 'sofisticação' crescente das armas, para a própria vida e a morte" (CARNOY, 1990, p. 9).

No século XIX, a força propulsora do capitalismo residia na produção da empresa privada, que acabava se tornando o centro da mudança social, pouco influenciada pela atuação estatal. Desde o surgimento do Estado, o gradual aumento da sua importância para o desenvolvimento das sociedades está relacionado com o processo não planejado da transição de sua administração pelo poder privado para as "mãos" do poder público. Neste momento, as funções dentro daquilo que viria a ser a máquina do Estado, e que eram ocupadas por familiares da casa real e pessoas ligadas mais diretamente ao rei, e os órgãos que nada mais eram que extensões e subdivisões dos interesses da família real, passam lenta e inevitavelmente a atender interesses não mais exclusivos do então governo absolutista ${ }^{4}$.

\footnotetext{
${ }^{3}$ Exemplo disso foi a participação decisiva do Estado na solução da crise econômica mundial, desencadeada a partir do ano de 2008 por conta de problemas financeiros nos Estados Unidos e que se espalhou por grande parte do planeta.

${ }^{4}$ Para mais informações sobre a formação do Estado moderno ver ELIAS, N. O Processo Civilizador. Rio de Janeiro: Zahar, v. 2, 1993. p.87-190.
} 
Segundo Linhales (1998), o Estado liberal clássico ${ }^{5}$ não compreendia a realização de direitos sociais ${ }^{6}$ como uma de suas atribuições, pronunciando-se como árduo defensor dos direitos civis, principalmente do direito à propriedade. Apresentava também restrições aos direitos políticos. Normalmente, os cidadãos considerados possuidores de direitos políticos eram aqueles que se encontravam na categoria de proprietários. Nesse período inicial o Estado cumpre basicamente a função de assegurar a paz (através da defesa de suas fronteiras e garantia de propriedade) e centralizar a arrecadação de impostos.

Esta situação se altera pelo contínuo processo de expansão dos direitos políticos e sociais ocorridos, essencialmente, no decorrer do século XX, apontando o fim do caráter restrito do Estado (LINHALES, 1998).

No momento em que o Estado é obrigado a atender interesses muito mais abrangentes - e não mais, de forma exclusiva, a interesses privados daqueles que reconhecidamente o controlavam - que a sua função cresce em importância para a sociedade. Com a evolução da economia e as crescentes divisões de funções, o Estado adquire outras obrigações, devendo solucionar diversos problemas e atender variadas demandas sociais, a fim de manter a paz, assegurar a ordem social e promover o desenvolvimento nacional (CARNOY, 1990).

Não mais apenas recolher impostos para defender o território e assegurar a paz é a função do Estado. O Estado passa a se responsabilizar por outras questões sociais, garantindo que direitos e deveres sejam cumpridos. A conquista de direitos e conseqüente ampliação da cidadania impôs ao Estado uma reformulação, no sentido de repensar novos conteúdos da agenda pública (LINHALES, 1998).

\footnotetext{
${ }^{5} \mathrm{Na}$ visão liberal clássica, o Estado ideal era aquele no qual o poder político era estendido a um grupo amplo, deixando que o mercado livre cuidasse da distribuição da riqueza e da renda (CARNOY, 1990). Pensando de maneira cronológica foi uma das primeiras concepções de Estado.

${ }^{6 "}[. .$.$] os direitos sociais permitem reduzir os excessos de desigualdade gerados pela sociedade$ de mercado e garantir um mínimo de bem-estar para todos" (MENICUCCI, 2006, p. 138). Esses só surgiriam bem mais tarde.
} 
De acordo com Carnoy (1990), o auge da responsabilidade do Estado para com os interesses públicos é observado tipicamente nas democracias pluralistas modernas ${ }^{7}$, algo mais próximo a nossa realidade atual, nas quais o povo:

[...] não levanta nem decide problemas, porém esses problemas, que moldam seu destino, são normalmente levantados e decididos para ele. Nessa teoria [pluralista], então, o Estado obtém um certo poder próprio - é ele que toma decisões quanto aos problemas, à legislação e ao curso do desenvolvimento econômico e social. Ao eleitorado cabe o poder de decidir qual grupo de líderes (políticos) ele deseja para levar a cabo o processo de tomada de decisão. (CARNOY, 1990, p. 51).

Portanto, é o Estado, ou melhor, os agentes eleitos ou escolhidos para administrar o Estado, quem elaboram as políticas públicas para os mais variados setores. Estes, organizados em arranjos políticos, por sua vez, "interferem na seleção de prioridades para a alocação dos recursos públicos, que são extraídos da população e que a ela deveriam retornar, redistributivamente, na forma de programas e serviços públicos" (LINHALES, 1998, p. 73).

Aqui se descortina o limite entre aqueles que estão no campo político/burocrático e seus respectivos subcampos produzindo políticas públicas, e aqueles "de fora", a quem apenas cabe eleger os que farão parte do "jogo".

O conceito de políticas públicas é aqui entendido como uma estratégia de intervenção e regulação do Estado (e daqueles que o administram), que objetiva alcançar determinados resultados ou produzir certos efeitos no que diz respeito a um problema ou a um setor da sociedade (MENICUCCI, 2006). São intervenções governamentais que resultam de intensa atividade político/burocrática

\footnotetext{
${ }^{7} \mathrm{~A}$ democracia pluralista moderna é definida por Schmitter (1964) citado por Carnoy (1990, p. 53) como, "Um sistema de representação de interesses no qual as unidades constituintes são organizadas em um número não-especificado de categorias múltiplas, voluntárias, competitivas, ordenadas não hierarquicamente e auto-determinadas., controladas pelo Estado na seleção da liderança ou articulação de interesse, e que não exercem o monopólio da atividade representativa de suas respectivas categorias".
} 
e que representam "decisões e ações revestidas da autoridade soberana do poder público" (RUA, 1997 citado por MENICUCCI, 2006, p. 142).

As ações governamentais que visam atender a sociedade com relação a uma determinada demanda são chamadas de políticas públicas setoriais. Construídas historicamente, num processo não linear de lutas sociais, conquista de direitos e mudanças de valores, as políticas sociais representam, hoje, o modo de intervenção estatal no que tange as questões sociais, mais especificamente, aquelas relacionadas à garantia dos direitos sociais (educação, saúde, trabalho, lazer, segurança, esporte, etc.). Estas ações pressupõem a atuação decisiva e operacional do Estado, já que "diferentemente dos direitos civis e políticos, a viabilização dos direitos sociais se faz pela intervenção ativa do Estado de forma positiva, ou seja, por meio das políticas sociais" (MENICUCCI, 2006, p. 139). Assim, os direitos sociais hoje:

[...] pressupõe a garantia e provisão, por parte do Estado, de políticas capazes de dar suporte ao bemestar de todos os cidadãos. Os conteúdos ou áreas sociais implicadas na promoção do bem-estar social constituem direitos mínimos e universais, conquistados historicamente. Devem ser compreendidos como uma construção decorrente dos múltiplos conflitos e interesses que legitimam as chamadas democracias capitalistas contemporâneas (LINHALES, 1998, p. 73).

Dentre as políticas sociais estão aquelas diretamente direcionadas ao âmbito do esporte e lazer, e também, aquelas que indiretamente interferem nessa esfera social, pois a complexidade de fatores que afetam o esporte e o lazer ultrapassa as barreiras setoriais tradicionais, demandando, portanto políticas públicas nos mais variados universos sociais.

Compreender que políticas públicas de esporte e lazer estão circunscritas a garantia do acesso a direitos sociais, que estão arranjadas como políticas setoriais, e que são uma estratégia do 
Estado para ocasionar um determinado impacto na sociedade, porém, não dão conta de entender a complexidade do processo de formulação e implementação dessas.

A primeira questão relevante diz respeito a própria semântica da palavra política. Na língua portuguesa a palavra pode ter variadas conotações, que no fundo se referem a diferentes etapas do processo político. Na língua inglesa, há diferenciação, através dos termos polity, politics e policy. Sumariamente, o primeiro termo designa as instituições políticas; o segundo, os processos políticos; e o último os conteúdos da política.

*A dimensão institucional 'polity' se refere à ordem do sistema político, delineada pelo sistema jurídico, e à estrutura institucional do sistema político administrativo;

*No quadro da dimensão processual 'politics' temse em vista o processo político, freqüentemente de caráter conflituoso, no que diz respeito à imposição de objetivos, aos conteúdos e às decisões de distribuição;

*A dimensão material 'policy' refere-se aos conteúdos concretos, isto é, à configuração dos programas políticos, aos problemas técnicos e ao conteúdo material das decisões políticas (FREY, 2000, p. 216-217).

$\mathrm{Na}$ realidade política as categorias, apresentadas de forma didática, estão entrelaçadas e se influenciando mutuamente. Para uma interpretação consistente são indispensáveis "representações modelares sobre possíveis concatenações explicativas" (KNOEPFEL, 1987 citado por FREY, 2000, p. 217), que podem ser obtidas através de estudos empíricos de cada arena ou setor da política. Os programas concretos, elaborados por agentes subscritos ao campo político/burocrático, devem ser considerados como resultado de um processo político, intermediado por estruturas legais e institucionais, que refletem constelações específicas de interesses. Com o direcionamento do olhar ao processo, tornam-se mais 
importantes os arranjos institucionais, as atitudes e objetivos dos agentes políticos, os instrumentos de ação e as estratégias políticas (FREY, 2000).

Estudos como o de Manhães (2002) privilegiam a dimensão polity das políticas públicas de esporte e lazer ao destacar o aparato legal que serviu de sustentação às políticas esportivas no Brasil. Estudos que tratam da dimensão politics no subcampo político/ burocrático do esporte e lazer são raros no Brasil, como aponta levantamento realizado por Amaral e Pereira (2009). A dimensão material policy é a mais recorrente nos estudos de esporte e lazer. Todavia, normalmente carecem de maior rigorosidade conceitual, constituindo-se como relatos de experiências ou relatos da empiria.

Dentro do processo político, ou politics, observa-se a constituição de redes, policy network, que Frey (2000, p. 221) debate citando as contribuições de Heclo (1978) e Miller (1994). Para Heclo, policy network são as "interações das diferentes instituições e grupos tanto do executivo, do legislativo, como da sociedade na gênese e na implementação de uma determinada 'policy'". Segundo Miller, são redes de relações sociais que se repetem periodicamente, menos formais que as relações institucionalizadas, mas suficientemente regulares, onde os integrantes estabelecem relações de confiança, compartilham opiniões e valores. Este modelo de rede constitui uma interpretação alternativa ao modelo institucional hierarquizado. Possui uma estrutura horizontal de competências, densidade comunicativa, e um controle mútuo intenso. Segundo Menicucci (2006), essas redes são formadas por um conjunto de agentes envolvidos na disputa pelo reconhecimento de uma questão como assunto público, e incluem desde a restrita comunidade de especialistas até grupos de interesse, movimentos sociais, redes societárias temáticas, atores governamentais, que por meio da cooperação buscam seus objetivos.

Além dos membros que constituem as policy networks, outros tantos podem estar se relacionando a elas em condições mais particulares. Neste caso, constituem redes chamadas de issue 
networks. No interior das redes estabelecidas, por vezes os agentes demonstram rivalidades e/ou solidariedades, de acordo com os objetos de disputa e o grau de rivalização com outras redes.

No caso das políticas públicas de esporte e lazer, acredita-se ser bastante pertinente o uso dos conceitos de policy network e issue networks, uma vez que dão a possibilidade de pensar as redes de relações entre agentes que extrapolam as dimensões institucionais formais ${ }^{8}$. Dada a pluralidade de agentes inseridos no campo esportivo, muitas vezes a análise da dimensão formal, ou mesmo o olhar apenas ao subcampo político/burocrático, dá uma visão apenas parcial do contexto de disputa e rivalidades entre os agentes. Trabalhando com a idéia de que as redes são dinâmicas e mutáveis pode-se avançar na compreensão das relações entre os agentes e na dimensão das cadeias de interdependências presentes, que muitas vezes envolvem outros campos ou subcampos. Casos pertinentes ao subcampo político/burocrático do esporte e lazer que poderiam ser interpelados a partir dessa perspectiva são os processos de formulação de legislação específica, como na redação do artigo 217 da Constituição Federal de 1988 e nas leis infra-constitucionais, onde foram constituídas policy networks e issue networks que fizeram valer a predominância de uma lógica específica do esporte, ou ainda nas recentes Conferências Nacionais do Esporte promovidas pelo governo federal.

Já no limite entre a lógica interna do campo político/burocrático e a lógica externa, difusa na sociedade, a concepção de policy arena parece útil. Nela destaca-se que as reações e expectativas das pessoas afetadas por medidas políticas têm um efeito antecipativo para o processo político de decisão e implementação. Os custos e ganhos que as pessoas esperam de tais medidas tornam-se decisivos para a configuração do processo político (FREY, 2000). Refere-se, portanto, aos processos de conflito e consenso dentro das diversas áreas da política, de acordo com supostos ganhos e perdas que o agir político pode ocasionar.

${ }^{8}$ Os conceitos seriam muito pertinentes, por exemplo, na análise dos agentes e grupos representados nas Conferências Nacionais do Esporte. 
No que diz respeito à dimensão temporal, Frey (2000) chama a atenção para o fato de que as redes e arenas das políticas setoriais podem sofrer transformações no decorrer da implementação das políticas. Nesse sentido, deve-se atentar ao caráter dinâmico do processo, bem como sua complexidade temporal. Portanto, além dos arranjos dos agentes, expressos nos conceitos de policy networks, issue networks e policy arena, deve-se pensar na temporalidade do processo político. Frey (2000) propõe para tanto uma subdivisão dos processos político-administrativos, a fim de desvendar as constelações de poder, as redes sociais e as práticas políticoadministrativas em cada uma das fases.

Apesar de diferenças entre as divisões tradicionais do ciclo político, são comuns na literatura as fases de formulação, da implementação e do controle dos impactos das políticas. Frey (2000, p. 226) indica, por sua vez, uma divisão um pouco mais sofisticada, distinguindo as seguintes fases: "percepção e definição do problema, 'agenda-setting', elaboração de programas e decisão, implementação de políticas e, finalmente, a avaliação de políticas e eventual correção da ação".

No que diz respeito à primeira fase "percepção e definição de problemas", Frey (2000) aponta que o que interessa ao analista de políticas públicas é como em um universo infinito de possibilidades de ações políticas, determinadas policy issues ${ }^{9}$ mostram-se apropriadas ao tratamento político, e acabam por gerar policy cycles (ciclos políticos). Determinado fato ou demanda pode ser levantado por grupos isolados, mas também percebido por políticos e pela administração pública. Fatores externos como a mídia e os lobistas ${ }^{10}$ podem ter um papel muito importante nesse processo. Porém,

\footnotetext{
${ }^{9} \mathrm{Ou}$ traduzindo livremente, uma questão que pode ou não ser tratada pelo Estado.

${ }^{10}$ Segundo a ementa de Projeto de Lei 1713 , de 18/08/2003, que tramitou na Câmara dos Deputados de 2003 a 2005 e que pretendia regulamentar a profissão de Lobistas, este por ser definido como "um agente de pressão junto à Administração Pública Direta e Indireta de qualquer dos poderes da União, dos Estados, do Distrito Federal e dos Municípios". Segundo o texto do projeto de lei, "Agente de Pressão" é "toda pessoa física ou jurídica, pública ou privada, que exerça, ainda que transitoriamente ou sem remuneração, por eleição, nomeação, designação, contratação ou qualquer outra forma de investidura ou vínculo, qualquer atividade tendente a influenciar o processo legislativo ou a tomada de decisões públicas". Disponível em http:// www.cosif.com.br/mostra.asp?arquivo=20060818lobista acesso em 03 de agosto de 2010.
}

Movimento, Porto Alegre, v. 17, n. 03, p. 233-251, jul/set de 2011. 
problemas do ponto de vista analítico só se transformam em problemas de policy a partir do momento em que adquirem relevância do ponto de vista político e administrativo (WINDHOFF-HÉRITIER, 1987 citado por FREY, 2000), ou seja, são incorporados como um interesse do campo político/burocrático.

No caso do esporte, a repercussão midiática, simbólica e de propaganda do esporte de alto-rendimento parece influenciar as opções por políticas públicas voltadas a essa manifestação do esporte. Reproduz-se, de forma mimética, lógicas e valores do alto-rendimento no processo de definição de problemas, que repercutem em um objeto tão plural quanto o esporte. Em síntese, parece-nos que o esporte de alto-rendimento (um policy issues) tem maior apelo para gerar um policy cycles do que outras manifestações do esporte.

Outro exemplo foi apontado por Azevedo (2004), que ao discutir a educação como uma demanda das políticas públicas, utilizou as contribuições de Muller (1985) e Jobert (1989b) para realizar a análise e fazer uma proposta analítica para a política educacional. Para a autora, Muller e Jobert superam os "construtos que se detiveram num enfoque econômico da intervenção pública, tal como os estudos vinculados à 'escola lógica do capital"' (AZEVEDO, 2004, p. 58). A perspectiva dos autores permite compreender a ação do Estado além da concepção abstrata das necessidades de acumulação, que pouco auxilia no entendimento do fenômeno em sua concretude e complexidade. Não que a dimensão econômica seja desprezada nesta linha de pensamento. Porém, o grau de importância das diferentes áreas ou setores está relacionado ao projeto de sociedade prevalecente, que extrapola a dimensão econômica:

Esse grau de importância pode ser discernido nos enleamentos da ação estatal com os conflitos de interesses intra e intersetoriais e com o ordenamento, articulação e hierarquização destes mesmos no que denominam 'referencial normativo global': o projeto de sociedade implantado num determinado período (AZEVEDO, 2004, p. 58). 
Ou seja, no momento de percepção e definição de problemas, a dimensão econômica nem sempre é a mais relevante quando da opção por determinadas prioridades. Essa opção é pautada em uma série de outros fatores, que envolvem inclusive o projeto societário. Há de se questionar, nesse caso, qual o espaço do esporte e do lazer no interior do projeto de sociedade que almejamos? Ou ainda: a sociedade compreende o que vem a ser o esporte e o lazer, e qual seu potencial na construção da mesma?

Com essas inquietações em mente, destaca-se que será somente no segundo momento, na fase do 'agenda-setting' que a decisão de se um tema será inserido na pauta política atual, se será excluído ou adiado. Para tanto, torna-se necessária uma avaliação preliminar sobre custos e benefícios das várias opções disponíveis de ação, bem como das possibilidades do tema ou projeto se imporem na arena política (FREY, 2000). Isso pode ser circunstancial, como na ocasião de uma crise econômica, ou algo incorporado, que demonstra certa regularidade, como na prioridade de determinadas áreas em detrimento a outras (economia à educação), ou no financiamento irrisório destinado ao esporte e a cultura, por exemplo.

Na fase de "elaboração de programas e de decisão" é preciso escolher a melhor forma de ação. Normalmente precedem ao ato de decisão propriamente dito, e envolvem processos de conflito e acordo entre os agentes mais relevantes da política e administração (FREY, 2000). Nessa fase se faz a opção técnica e metodológica nas políticas. Nesse momento, os profissionais técnicos envolvidos, como os professores de educação física nas Secretarias Municipais e Estaduais de Esporte e Lazer podem ter papel relevante, desde que se apresentem como agentes relevantes, especialmente pelo seu capital cultural específico.

No próximo passo, processo de "implementação das políticas", Frey (2000) distingue duas possibilidades de análise: a primeira diz respeito à análise da qualidade material e técnica de projetos e programas, e a segunda direcionada para as estruturas políticoadministrativas e a atuação dos agentes envolvidos. No primeiro 
caso torna-se importante o conteúdo dos programas e planos; no segundo, o que mais importa é o processo de implementação, descrevendo como e por que foi feito.

Na fase de "avaliação de políticas e da correção de ação", analisam-se os impactos efetivos dos programas já implementados, podendo ocorrer durante seu funcionamento ou após sua finalização. Trata-se de levantar os déficits de impacto e os efeitos indesejados, buscando redimensionar ações e programas futuros, ou ainda registrar potencialidades e acertos para serem replicadas em futuras ações, constituindo um passo fundamental à aprendizagem política. Essa etapa é pouco observada no interior do subcampo político/burocrático do esporte e lazer, onde prevalece a lógica do empirismo (CAVICHIOLLI, 1996) e da falta de avaliação.

Frey (2000) chama a atenção ao caráter didático e analítico de seu modelo de policy cycle, uma vez que na política real ou efetiva, muitas vezes os passos se sobrepõe ou se confundem. Ao comparar processos reais com o tipo puro podemos obter pontos de referência que nos fornecem pistas de possíveis problemas no processo de implantação de políticas setoriais. Constitui, portanto importante ferramenta metodológica a ser utilizado pelos pesquisadores que estudam o subcampo político/burocrático do esporte e lazer.

\section{Considerações Finals}

As reflexões aqui apresentadas visam contribuir com uma leitura mais refinada das políticas públicas de esporte e lazer por parte dos especialistas. São conceitos e procedimentos metodológicos oriundos de outros campos do conhecimento, que podem ser apropriados pelos agentes/pesquisadores do subcampo científico/ acadêmico da Educação Física, no intuito de alavancar a qualidade dos estudos na área.

Em outras oportunidades (STAREPRAVO, 2007; STAREPRAVO; MEZZADRI, 2007), pudemos constatar a proliferação de estudos de casos e relatos de experiência de maneira 
horizontal, sem um avanço qualitativo. Mais tarde (STAREPRAVO; NUNES; MARCHI JR., 2009) observamos a dificuldade dos pesquisadores em aliar a pesquisa empírica de fôlego com a discussão teórica e metodológica das políticas públicas.

Esperamos aqui ter contribuído no sentido de superação do status quo da área. Essa superação, porém, só se dará a partir do debate acadêmico e do desenvolvimento do subcampo científico/ acadêmico das políticas públicas de esporte e lazer. Nesse sentido fica o convite a novas contribuições, críticas e debates públicos no subcampo científico/acadêmico das políticas públicas de esporte e lazer, a fim de avançarmos cada vez mais. 


\section{Public Policies for Sport and Leisure in Brazil:} an Proposed of Theoretical-Methodological Analysis

Abstract: This essay seeks to contribute to a more refined public policies for sports and leisure from specialists through some thoughts, concepts and methodological procedures, which are a fundamental part of the search tools social researcher, particularly those looking for a reading sociocultural sport, leisure and related topics. For both authors revisit some field of science / academic Physical Education and resorted to some agents from other areas of knowledge that can help with their contributions in overcoming the horizontal proliferation of scientific production, promoting its vertical growth, in quality.

Keywords: Public policies. Sports. Leisure Activities. Methods.

\section{Políticas Públicas para el Deporte y el Ocio en Brasil: Una Propuesta Teorico Medodologica de Análisis}

Resumen: Este artículo busca contribuir con una lectura más refinada de las políticas públicas para el deporte y el ocio por parte de los especialistas, a través de algunas reflexiones, conceptos y procedimientos metodológicos, que son una parte fundamental de las herramientas de estudios del investigador social, en particular de aquellos que buscan uma lectura sociocultural Del deporte, del ocio y de temáticas relacionados. Para ello revisamos algunos autores del campo científico-académico de Educación Física, y también recurrimos a fuentes de otras áreas del conocimiento, que con su contribución pueden ayudar a superar La proliferación horizontal de producción científica en el área, promoviendo su crecimiento vertical, con calidad.

Palabras clave: Política Pública. Deportes. Actividades Recreativas. Métodos. 


\section{REFERÊNCIAS}

AMARAL, S. C. F; PEREIRA, A. P. C. Reflexões sobre a produção em políticas públicas de Educação Física, esporte e lazer. Revista Brasileira de Ciências do Esporte, Campinas, v. 31, n. 1, p. 41-56, 2009.

AZEVEDO, J. M. L. de A. A educação como política pública. 3. ed. Campinas, SP: Autores Associados, 2004.

BOURDIEU, P. A casa do rei à razão de Estado: um modelo da gênese do campo burocrático. In: WACQUANT, L. O mistério do ministério: Pierre Bourdieu e a política democrática. Rio de Janeiro: Revan, 2005. p. 41-70.

CARNOY, M. Estado e Teoria Política. 3. ed. Campinas, SP: Papirus. 1990.

ELIAS, N. O Processo Civilizador. Rio de Janeiro: Zahar, 1993. v.2

FREY, Klaus. Políticas públicas: um debate conceitual e reflexões referentes à prática da análise de políticas públicas no Baril. In: Planejamento e Políticas Públicas. Brasília, n. 21, p. 211-259, jun. 2000.

$<$ http://www.cosif.com.br/mostra.asp?arquivo=20060818lobista $>$. Acesso em: 03 ago. 2010.

LINHALES, M. A. São as políticas públicas para a educação física/esportes e lazer, efetivamente políticas sociais? Motrivivência, Florianópolis, n. 11, p.71-81, set. 1998.

MANHÃES, E. D. Políticas de esportes no Brasil. 2. ed. Rio de Janeiro: Graal, 2002.

MARCHI JR. W. A educação física e o campo científico: repensando as possibilidades de pesquisa sobre o esporte e o lazer. In: MEZZADRI, F. M.; CAVICHIOLLI, F. R.; SOUZA, D. L. de. Esporte e Lazer: subsídios para o desenvolvimento e gestão de políticas públicas. Jundiaí: Fontoura, 2006.

MELO, M. A. Estado, governo e políticas públicas. In: MICELI, S. (org.). O que ler na ciência social brasileira (1970-1995). São Paulo: Brasília: Sumaré, Anpocs, Capes, 1999. v. 3, p. 59-100.

MENICUCCI, T. Políticas Públicas de lazer. Questões analíticas e desafios políticos. In: ISAYAMA, H. F., LINHALES, M. A. Sobre Lazer e Política: maneiras de ver, maneiras de fazer. Belo Horizonte: Editora UFMG, 2006. p.136-164.

STAREPRAVO, F. A. Políticas públicas para o esporte e lazer: conselhos municipais de esporte e lazer e outras formas de participação direta. In: Anais do XV Congresso Brasileiro de Ciências do Esporte [e] II Congresso Internacional de Ciências do Esporte / Colégio Brasileiro de Ciências do Esporte. Recife: CBCE, 2007. 
STAREPRAVO, F. A.; MEZZADRI, F. M. Algumas contribuições de Pierre Bourdieu e Norbert Elias à discussão de políticas públicas para o esporte e lazer. In: Anais do X Simpósio Internacional Processo Civilizador. Campinas, 2007.

STAREPRAVO, F. A.; NUNES, R. J. S.; MARCHI JR., W. Agenda de pesquisa em políticas públicas de esporte e lazer: uma leitura a partir do GTT de Políticas Públicas no XV Congresso Brasileiro de Ciências do Esporte. In: Anais do XVI Congresso Brasileiro de Ciências do Esporte [e] III Congresso Internacional de Ciências do Esporte / Colégio Brasileiro de Ciências do Esporte. Salvador: CBCE, 2009.

Apoio: CAPES-REUNI

Endereço para correspondência

Fernando Augusto Starepravo

Universidade Estadual de Maringá (UEM)

Departamento de Educação Física

Avenida Colombo, 5.790

Campus Universitário

CEP 87.020-900

Maringá-PR

Recebido em: 27-01-2011

Aprovado em: 10-08-2011

Dovimento, Porto Alegre, v. 17, n. 03, p. 233-251, jul/set de 2011. 
